\title{
Consumers' Trust and Popularity of Negative Posts in Social Media: A Case Study on the integration between B2C and C2C Business Models
}

\author{
Sinan S. AlSheikh \\ Senior Solution Architect, IBM \\ Dubai, UAE \\ Sinan@ae.ibm.com
}

\author{
Khaled Shaalan \\ Faculty of Engineering \& IT \\ The British University in Dubai UAE \\ Honorary Fellow, School of Informatics, \\ University of Edinburgh, UK \\ khaled.shaalan@buid.ac.ae
}

\author{
Farid Meziane \\ School of Computing Science \& \\ Engineering, University of Salford, \\ Manchester, England \\ f.meziane@salford.ac.uk
}

\begin{abstract}
Trust can be defined as the vulnerability of trustor towards trustee to meet certain expectations. This paper extends the definition of trust to cover digital world and illustrate the trust model used by most of nowadays online stores. The social media sentiment analysis revealed the sentiments of customers towards traditional Business-to-Consumer (B2C) stores vs modern Consumer-to-Consumer (C2C) market places. Sentiment analysis was performed across multiple industry's like Taxi, hospitality, and online retail industry. The popularity of Negative sentiments was higher towards most of modern C2C market places compared to traditional $\mathrm{B} 2 \mathrm{C}$ stores. The popularity of negative posts was linked with the consumers' trust towards the C2C market place offering. However, few C2C companies managed to maintain a high positive posts ration and sometimes they were better than traditional B2C business. Uber and AirBnB surprisingly were not on the top.
\end{abstract}

Keywords-Trust; Trust worthiness; Social Media; Sentiment Analysis;B2C; C2C;

\section{INTRODUCTION}

The concept of Trust is widely addressed in various studies. In the literature, it is indicated that there is a mix with other concepts, such as Risk, Privacy and Security [1]. Some of these concepts overlap at a point in time and contribute to the success or failure of online commercial transactions, but each of which has its own definition that influences buyers and seller differently.

Trust can be defined as the vulnerability of trustor (e.g. buyers) towards trustee (e.g. sellers) to meet certain expectations (e.g. quality of a produce). In traditional ECommerce B2C, Trust is considered as one directional emotion where buyers need to trust Sellers to complete a transaction as expected. In this framework:

- $\quad$ The level of trust from buyers to these stores are very strong and very hard to be changed

- Deals, especially in local markets, are provided through few online centralized commercial stores

- Individuals prefer to finalize their deals with highly reputational E-Commerce shops
In Modern E-Commerce, Trust is evolved to be bidirectional emotion, where buyers need to trust sellers, and the vice versa, in order to complete a transaction (C2C). In this framework:

- The spectrum has become wider and the complexity has also become higher for finalizing a deal online within short timeframe. This is apparent in market places similar to Uber, Airbnb, among others.

- The competition is not only limited to items offered by commercial stores but also any individual can offer products, such as a car and apartment, or provide any services online.

The scope of this study involves trust among users while performing an E-Commerce transaction of a deal online. A transaction which involves an exchange of money for a service/product between sellers and buyers over the internet.

In this study, we propose an E-Commerce model that integrates the Business to Consumer (B2C) model with the Consumer to Consumer (C2C) model. For these particular ECommerce model, buyers and sellers have personal, psychological, social and cultural characteristics that influence their own decision to establish or finalize a deal online [10] [11]. This paper focuses on trust and its psychological impact on buyers and sellers while performing a deal.

\section{OBJECTIVE}

The objective of this research is to extend the definition of trust from the physical world to cover people sentiments on the digital world while performing transactions. This research will also perform a social media analysis to revel Customer's sentiments towards traditional business model (B2C) and compare it to those towards modern business model $(\mathrm{C} 2 \mathrm{C})$. The paper aims to define a new view towards Customer's trust in order to reduce the popularity of negative posts. 


\section{A. Definition of trust}

In the literature, there are various studies that shed the light on the concept of Trust within E-Commerce. Unfortunately, there is a mix-up with other concepts, including Risk, Privacy and Security [1]. Some of these concepts overlap at a point in time and contribute to the success or failure of online transactions, as each one of them influences the decision of either the buyer or the seller differently. An attempt to define the concept of Trust is better explained in a situation characterized by the following aspects:

"One party (trustor) is willing to rely on the actions of another party (trustee); the situation is directed to the future. In addition, the trustor (voluntarily or forcedly) abandons control over the actions performed by the trustee. As a consequence, the trustor is uncertain about the outcome of the other's actions; they can only develop and evaluate expectations. The uncertainty involves the risk of failure or harm to the trustor if the trustee will not behave as desired." [6]

There are other attempts to define the concept of trust; however, they all share the same three parts [12]: trustor, trustee, and expectations. The trustor abandons the control and builds expectations on the results from the trustee. Another attempt to define the concept of trust with more focus on the digital domain would be:

"Trust is the confidence placed in an organization (trustee) to collect, store and use the digital information of others (trustor) in a manner that benefits and protects (expectations) those to whom the information pertains" [2].

\section{B. Trust as an emotion}

Another research looks at trust as one of eight fundamental basic emotions (aka Plutchik's Wheel of Emotions [7]). They start with Joy, Trust, Fear, Surprise, Sadness, Disgust, Anger, Anticipation (e.g. Figure 1). Each emotion also has a stronger, and weaker form as shown in Table 1. For example, acceptance is the weaker form of Trust, while Admiration is the strongest form of rust.

Table 1: Strength of emotion

\begin{tabular}{|c|c|c|}
\hline Weaker & Normal (Basic) & Stronger \\
\hline Serenity & Joy & Ecstasy \\
\hline Acceptance & $\leftarrow$ Trust $\rightarrow$ & Admiration \\
\hline Apprehension & Fear & Terror \\
\hline Distraction & Surprise & Amazement \\
\hline Pensiveness & Sadness & Grief \\
\hline Boredom & Disgust & Loathing \\
\hline Annoyance & Anger & Rage \\
\hline Interest & Anticipation & Vigilance \\
\hline
\end{tabular}

Moreover, the Plutchik's wheels of Emotions suggests additional eight emotions each of which composed of two basic emotions: Love, Submission, Awe, Disapproval, Remorse, Contempt, Aggressiveness, and Optimism

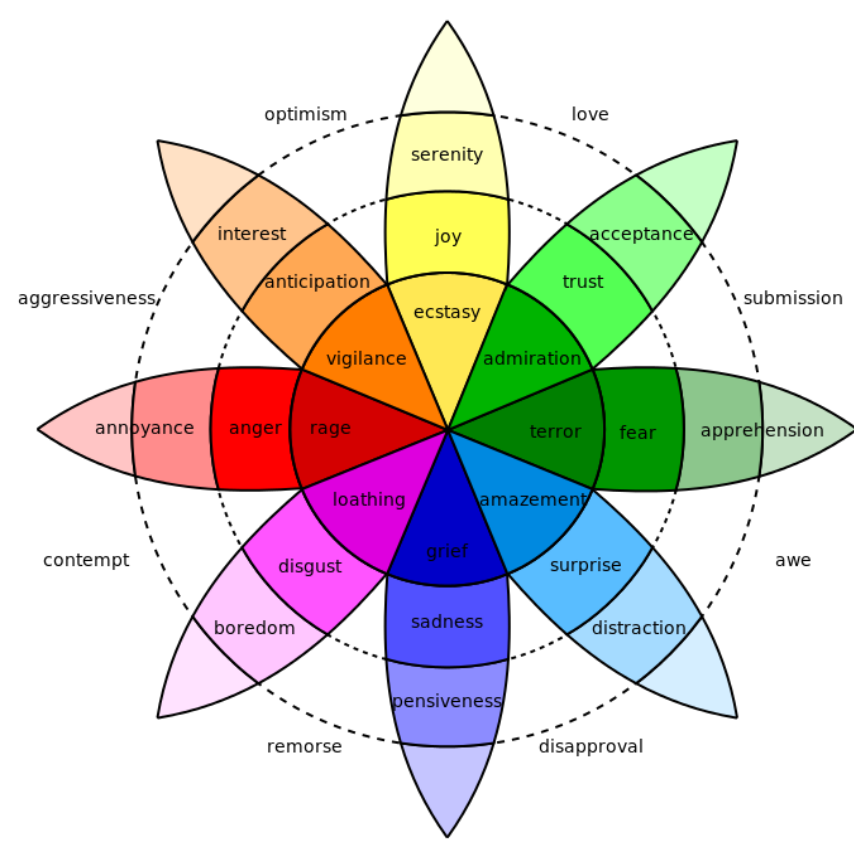

Figure 1: Plutchik's wheels of Emotions [Ref A7]

People agreed that certain acts can trigger emotions in other people. For example, threatening people can trigger fear, while talking about missed beloved ones can trigger sadness. There are other acts that can trigger anger, disgust, surprise and anticipation. Having said that, there must be an act or a sequence of acts that are responsible to trigger trust emotion in other people.

If emotions can be considered as body state, feelings are considered mental experience of current emotion [8]. While basic emotions are instinctual and common to all of us, feelings can differ from a person to another based on past and present experiences. In this research, we will focus on the concept of trust as a basic emotion not as just a feeling.

\section{Behavior of Buyers and Sellers commencing deals}

In E-Commerence, Both Buyers and Sellers are essential in any deal. They have their own wants and needs that should be satisfied in order to finalize the deal. The process of finalizing a deal is also known as the process of trade-offs between buyer and seller in order to reach a state that satisfy both sides [10].

When a buyer or a seller is represented by an organization, the behaviour and trade-offs might be structured and documented by this organization. For example, an organization might have a rule to only engage in potential deals if the profit margin is $10 \%$ or higher. On the other hand, if the buyer or the seller is a single individual or group of individuals, the wants and needs vary and the trade-offs have no structured form. This adds ambiguity to the overall deal [10].

The following list highlights the main characteristics that influence a consumer's behavior in approaching deals [10] [11]: 
- Personal Characteristics, which include gender, age, weight, occupation, income status, education and life style

- Psychological Characteristics, which include consumers affected by a psychological state at the time of finalizing the deal. An individual emotion (e.g. Joy, Anger, Trust, or fear) can be a deal maker or breaker.

- Social Characteristics, which include, but not limited to, the social opening of similar transaction. Other buyer's reviews and comments can put pressure on the consumer to whether or not to finalize a deal.

- Cultural Characteristics, which include the collective mental programming of the mind for an individual or group. This distinguishes members of one group of people from another.

Trust between buyers and sellers is considered as one of the psychological characteristics which influences the decisionmaking processes. Which is different from business model to another:

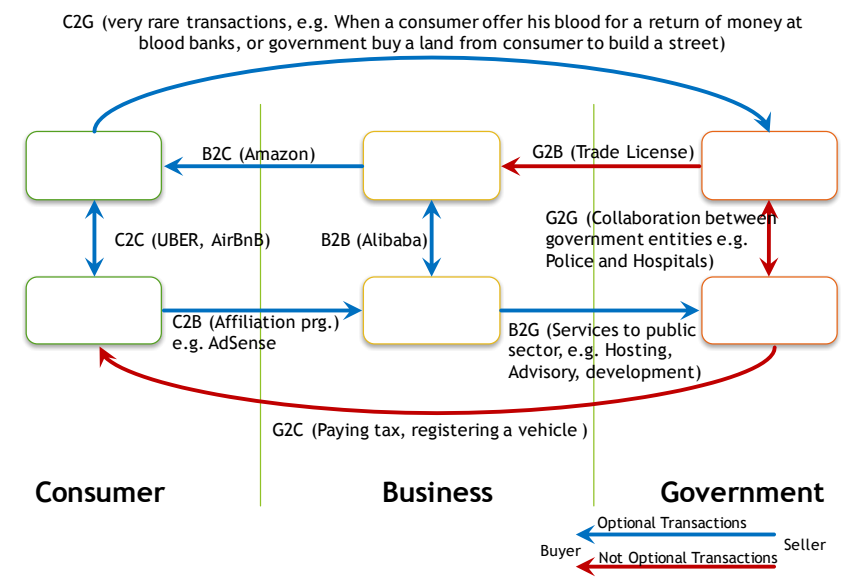

Figure 2: E-commerce abstract models

The paper focuses on Business to Consumer (B2C) and Consumer to Consumer (C2C) business model

\section{Conclusion}

Despite the fact that trust can be defined in many ways, it consists of three main parts: trustor, trustee, and expectations. The more dependent and vulnerable the trustor is on trustee to meet the expectation, the greater the need for trust. The probability in meeting the expectation is the level of trust. The aim of this paper is to define a mathematical model that would make it possible to calculate (measure) the probability of trustee to meet the expectation of trustor.

Trust is a basic emotion that has a psychological impact on human body. It can influence our behaviour and decisions while finalizing deals and performing actions. Like any other human emotion, trust can be synthesized chemically and can be triggered naturally.

\section{DATA COLLECTION AND ANALYSIS OF SENTIMETNS}

On an attempt to study the consumer's trust level towards B2C and $\mathrm{C} 2 \mathrm{C}$ market places, a sentiment data collection and analysis was performed using SocialMention tool to reveal the positive and negative sentiments mentioned by consumers. These sentiments are publicly available online by twitter, Raddit, Photobucket, Topic, and other blogs and sites. The accuracy and precision of SocialMention is out of the scope of this paper. However, the same tool will be used on all search queries to give fair inferences.

Three E-commerce case studies were considered in the sentiment analysis: Taxi Industry, Hotel Industry, and Retail Industry. The data analysis covers only the negative sentiments.

\section{A. Taxi Industry}

Uber, Hailo, Lyft, and GrabTaxi were selected for this case study as representative examples of modern taxi companies built on the $\mathrm{C} 2 \mathrm{C}$ model. On the other hand, Hackney carriage, Taxicab were selected to represent traditional taxi companies built on the B2C model. It is safe to assume that any mention (post) that contains one of selected brand names would refer to the company itself. Few other companies were excluded from the analysis because their brand names can be used in different context other than the brand itself, for example (Ola, and Via).

The following table summarizes the frequency of positive and negative sentiments analysis for all companies in less than a minute. There is at least one mention (post) per minute for each company over twitter, Raddit, Photobucket, Topix and many other blogs.

Table 2: Sentiment analysis for Taxi companies in less than a minute

\begin{tabular}{|c|c|c|c|c|c|}
\hline & Model & Positive & Neutral & Neg. & $\begin{array}{c}\text { Neg. } \\
\text { Sentiment }\end{array}$ \\
\hline Taxicab & B2C & 138 & 59 & 7 & $5 \%$ \\
\hline GrabTaxi & C2C & 84 & 36 & 12 & $14 \%$ \\
\hline Hackney Carriage & B2C & 117 & 50 & 16 & $14 \%$ \\
\hline Lyft & C2C & 156 & 67 & 31 & $20 \%$ \\
\hline Hailo & C2C & 114 & 49 & 29 & $25 \%$ \\
\hline Uber & C2C & 148 & 63 & 37 & $25 \%$ \\
\hline
\end{tabular}

As shown in Table 2, the percentage of negative sentiments of modern taxi companies (Uber, Hailo, and Lyft) is more than traditional taxis. Uber and Hailo had 1 negative post for every 4 positive posts (1:4 ratio), while Hackney Carriage had 1 negative post for every 7 positives posts (1:7 ratio). This makes the sentiments towards Hackney Carriage almost twice as positive compared to Uber and Hailo. On the other hand, Taxicab had 1 negative for every 20 positive posts (1:20 ratio) which makes the sentiment towards Taxicab 5 times more positive compared to Uber and Hailo. Notice that neutral posts with neutral sentiments were removed from this calculation.

Figure 3 shows the main categories of negative tweets related to UBER company. The lowest percentage was about price. The highest percentage was about Uber Drivers with regard to their unexpected behaviour and navigation experience. For example, some drivers cancelled requests from passengers who were waiting for half an hour to get a ride to rush to the airport leaving them in a situation that risked their flight. Others, lost their flights already while drivers were trying to figure out the directions to the airport. In general, Uber drivers didn't meet the expectations of their passengers 
and made many mistakes before, during and after the journey starts. Uber passengers (trustors) hired Uber driver (trustee) to pick them up on $\mathrm{X}$ min and transport them from point $\mathrm{A}$ to point B within the $\mathrm{Y}$ time prompted on the App (expectation). When an expectation is not met, the trust relationship is negatively affected. Trustors are impacted and express themselves in negative posts as an indication of unsatisfied trustor. On the other hand, traditional taxis uses a simplified expectation between trustors and trustees which is to transport passengers from point $\mathrm{A}$ into point $\mathrm{B}$ excluding other commitments offered by a sophisticated App.

It is uncommon to find negative tweets from drivers towards passengers. The majority of the tweets were from passengers complaining on drivers and not the other way around.

An interesting findings about GrabTaxi, a modern taxi company following $\mathrm{C} 2 \mathrm{C}$ business model, is that the sentiments towards this particular company is twice as good as Uber and equivalent to traditional taxi's that follow B2C business model like Hackney Carriage.

\section{UBER \\ NEGATIVE SENTIMENTS CATEGORIES}

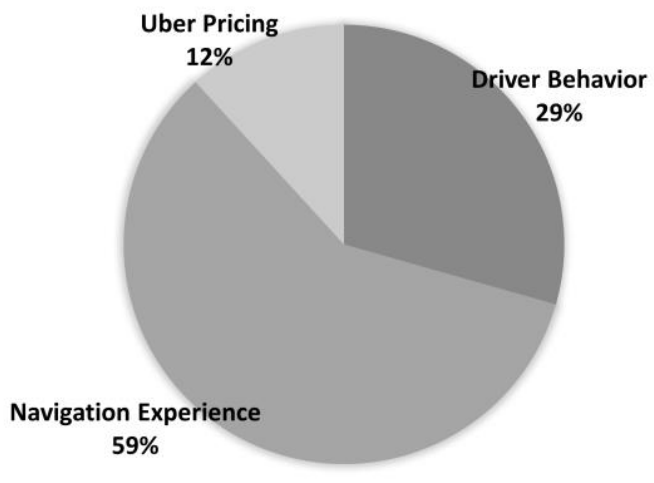

Figure 3: UBER Negative Sentiment Categories

After further analysis and detailed comparisons between all companies, we found that the difference between GrabTaxi and other modern companies, like Uber, is in the process of hiring drivers. GrabTaxi had connected their process to accept drivers into physical government roads and transportation authority in the country, while Uber, Hailo and Lyft had a relatively relaxed process.

In order to become a taxi driver for GrabTaxi, you have to have a government trade license under your name and register yourself as a taxi company. So, the car registration need to be changed from being individually owned into a company property that is used as taxi. You have to post GrabTaxi logos on the car to identify it as a GrabTaxi car. These processes made GrabTaxi more like B2C rather than its original model of $\mathrm{C} 2 \mathrm{C}$. On the other hand, Uber, Hailo and Lyft require only a police report and a valid driver license to start working for them.

In other words, when a driver is fully committed and identified to the government to practice Taxi driving as a profession, the driver behaviour changes accordingly. Moreover, the driver might avoid doing certain actions specially after knowing that any misbehaviour can yield into legal implications and discontinuity of their profession.

\section{B. Online Hospitality services Industry}

The sentiment analysis study was performed on Airbnb, CouchSurfing, Homeaway, and Vrbo as new market places for people to offer rental spaces under the $\mathrm{C} 2 \mathrm{C}$ model. Compared to other market places that offer only registered hotels and hotel apartments like Trivago, and Expedia which mostly follow B2C business model. Few other companies were excluded from the analysis due to the similarity of their brand names with other dictionary words (booking, kayak, Tripping) Table 3 summarizes the frequency of positive and negative sentiments as per SocialMention analysis in less than a minute. It also shows the frequency of mentions (posts) for all companies. There is at least one mention (post) per minute for each company over twitter, Raddit, Photobucket, Topix and many other blogs.

Table 3: Sentiment analysis for Hospitality companies in less than a minute

\begin{tabular}{|c|c|c|c|c|c|}
\hline & Model & Positive & Neutral & Neg. & Neg. Sentiment \\
\hline Vrbo & C2C & 98 & 42 & 5 & $5 \%$ \\
\hline Expedia & B2C & 63 & 27 & 4 & $6 \%$ \\
\hline Home Away & C2C & 84 & 36 & 6 & $7 \%$ \\
\hline Trivago & B2C & 82 & 35 & 14 & $17 \%$ \\
\hline Couch Surfing & C2C & 102 & 44 & 25 & $25 \%$ \\
\hline AirBnb & C2C & 123 & 53 & 41 & $33 \%$ \\
\hline
\end{tabular}

The sentiments towards $\mathrm{C} 2 \mathrm{C}$ market places in Hotel industry like (Airbnb, and Couch Surfing) were more negative than market places that are specialized in registered hotels B2C model (Expedia, Trivago). Airbnb had 1 negative post for every 3 positive posts (1:3 ratio), while Trivago had 1 negative for every 6 positives posts (1:6 ratio). This makes the sentiments towards Trivago 2 times more positive compared to Airbnb. Moreover, Expedia had ratio of 1:17 which makes it 6 times more positive than Airbnb.

This table also shows that Vrbo and Home Away are in the same level as Expedia and Trivago in terms of consumer's sentiments in the public domain. After deeper analysis, we found that Vrbo and Home Away has firmer rules for listing properties online. The websites, does not allow any property to be listed on the public domain until the host properly identify him/her self. All properties are suspended until the host links with a valid payment method such as credit card details or bank account. On the other hand, Airbnb accepts almost everyone with minimal quality assurance and identity verification. In order to verify this, we created a virtual property in Dubai and filled all the required fields with a description of a house. Then, we uploaded fake photos and assigned a location randomly. This property was promptly listed on Airbnb public site within minutes. We also received a confirmation email from Airbnb congratulating us on our first published property. Pls. refer to the appendix for a screen shot and an email confirmation. 


\author{
AirBNB \\ Negative Sentiments Categories \\ Guest Behavior \\ $8 \%$ \\ Customer Service \\ $21 \%$ \\ Trust and Safety \\ $17 \%$ \\ Unexpected Facility \\ $54 \%$ \\ Figure 4: Airbnb Negative Sentiment Categories \\ When the host is fully identified to the site, the host behavior \\ changes accordingly. Moreover, the host might avoid \\ untruthful act if it gets to know that there is a misbehavior from \\ any of the customers which might lead to financial implications \\ and discontinuity of their profession.
}

Figure 4 shows the main categories of negative tweets related to Airbnb company. The highest percentage of the negative tweets was about unexpected facility provided by the host. The description online does not meet reality. The second percentage in popularity is Airbnb customer service. The third percentage in popularity is due to the reason of the lack of trust and safety feeling while living with the host.

\section{Online Retail Industry Sentiment Analysis}

Another sentiment analysis study was performed on Amazon, eBay as a reseller of goods online with no physical stores vs BestBuy, RadioShack, Carrefour and Aldi as a Brick and mortar store to resell relatively similar goods.

Table 4 summarizes the frequency of positive and negative sentiments as per SocialMention analysis in less than a minute. It also shows that the frequency of mentions (posts) for all companies. There is at least one mention (post) per minute for each company over twitter, Raddit, Photobucket, Topix and many other blogs.

Table 4: Sentiment analysis for Retail companies in less than a minute

\begin{tabular}{|c|c|c|c|c|c|}
\hline & Model & Positive & Neutral & Neg. & Neg. Sentiment \\
\hline Aldi & B2C & 93 & 40 & 4 & $4 \%$ \\
\hline Radio Shack & B2C & 63 & 27 & 3 & $5 \%$ \\
\hline Carrefour & B2C & 132 & 56 & 7 & $5 \%$ \\
\hline BestBuy & B2C & 142 & 61 & 14 & $10 \%$ \\
\hline eBay & C2C & 92 & 39 & 18 & $20 \%$ \\
\hline Amazon & B2C, C2C & 105 & 45 & 26 & $25 \%$ \\
\hline
\end{tabular}

The sentiments towards online E-Commerce with no physical stores (Amazon, eBay) were more negative than Brick and mortar stores. Amazon had 1 negative post for every 4 positive posts (1:4 ratio), while BestBuy had 1 negative for every 10 positives posts (1:10 ratio). This makes the sentiments towards BestBuy 3 times more positive compared to Amazon.
Moreover, Carrefour had 1 negative for every 20 positive posts (1:20 ratio) which makes the sentiment towards Carrefour 5 times more positive compared to Amazon.

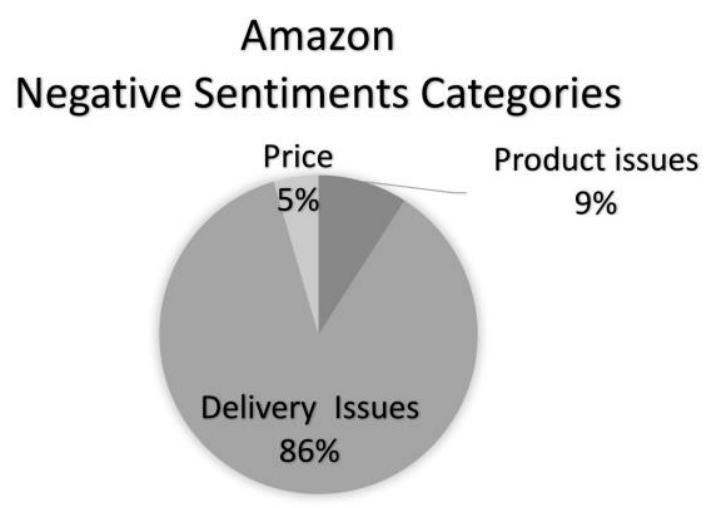

Figure 5: Amazon Negative Sentiment Categories

Figure 4 shows the main categories of negative tweets related to Amazon company. The lowest percentage was about product issues, and prices whereas the highest percentage was about delivery issues.

\section{CONCLUSION}

The sentiment analysis of the online Taxi's Industry showed that people sentiments towards B2C companies is more positive than $\mathrm{C} 2 \mathrm{C}$ companies. People tend to complain about Driver's behavior and lack of navigation experience in local roads. However, GrabTaxi was the exception. Although the company is built as $\mathrm{C} 2 \mathrm{C}$ model but people sentiments were more positive compared to others. After detailed comparison between GrabTaxi and other C2C companies like Uber, Lyft, Hailo, the process of hiring a driver is firmer and integrated with the physical government of the country.

The sentiment analysis of the online hospitality business showed that people sentiments towards registered hotels are more positive than $\mathrm{C} 2 \mathrm{C}$ companies. People tend to post negatively about fake, dirty facility, and untrusted hosts. However, Home Away and Vrbo were more successful in terms of positive posts. A possible reason for this difference is the firm process of accepting any host to publish a property through their websites. The website, doesn't allow any property to be listed publicly until the host properly identify him/her self by linking a valid credit card details or bank account. On the other hand, Airbnb accepts almost everyone with minimal quality assurance and identity verification.

The sentiment analysis of the online retail industry showed that people sentiments towards online stores with physical presents like BestBuy, Carrefour, Aldi are more positive compared to only online stores like Amazon and eBay. Most of the negative sentiments shared publicly were classified towards delivery problem.

\section{CONCLUSION}

This paper focuses on trust and its psychological impact on buyers and sellers while performing a deal. Sentiment analysis 
was performed across multiple industry's such as Taxi, hospitality, and online retail industry. The popularity of Negative sentiments was higher towards most of modern C2C market places compared to traditional B2C stores.

Modern $\mathrm{C} 2 \mathrm{C}$ E-commerce that hires ordinary people to perform commercial activities showed more negative sentiments compared to those that embedded their process with physical world. Modern $\mathrm{C} 2 \mathrm{C}$ E-commerce that involved a physical validation for their users showed more positive sentiments.

At the end, the paper extends the definition of trust to cover digital world and illustrate the trust model used by most of online stores. The trust relationship between buyers and sellers that is used in online stores is built on low trust relationship. Trustee has low impact in satisfying the expectation of the relationship.

\section{REFERENCES}

[1] Pennanen, K., Kaapu, T., \& Paakki, M. K. (2006). Trust, risk, privacy, and security in e-commerce. Proceedings of the International Conference on Electronic Business (ICEB).
[2] Accenture. (2015). Unleashing Business Value in a Digital World, 50.

[3] PwC. (2014). The confidence to take risks. Building Digital Trust, (March).

[4] Consulting, B. D. O., \& International, B. D. O. (2014). Cybersecurity and the Role of Trust in the Digital World.

[5] Paper, C. (2016). Blockchain - the Gateway To Trust-Free Cryptographic Transactions, (May), 0-14.

[6] Mayer, R. C., Davis, J. H., \& Schoorman, F. D. (1995). An integrative model of organizational trust. Academy of Management Review, 20(3), 709-734

[7] Plutchik, R. (2001). The nature of emotions: Human emotions have deep evolutionary roots. American Scientist.

[8] Arnold, Magda B., ed. Feelings and emotions: The Loyola symposium. Vol. 7. Academic Press, 2013

[9] Niranjanamurthy, M., Kavyashree, N., \& Chahar, S. J. D. (2013) Analysis of E-Commerce and M-Commerce : Advantages, Limitations and Security issues. International Journal of Advanced Research in Computer and Communication Engineering, 2(6), 2360-2370.

[10] Burnett, J. (2012). Understanding Buyer Behavior. Core Concepts of Marketing, Chapter 4, 1-26.

[11] Yoldas, S. (2011). Research Abt Buying Behavior Among Online Customers: Comparison of Turkey with UK, 1-69. Retrieved from

[12] Robert F. Hurley, The Decision to Trust (Harvard Business Review the September 2006 Issue). 